\title{
Opinion and use of contraceptives among medical students of the University of Nigeria, Enugu campus
}

\author{
Chinedu Arthur Idoko ${ }^{1}$, Babatunde Omotowo ${ }^{1}$, Charles Anyaka², Kenechukwu Udo ${ }^{3}$, \\ Osita Ezenwosu ${ }^{4}$, Emmanuel Nwobi ${ }^{1}$, Uche Ezeoke ${ }^{1}$, Ikechukwu Obi ${ }^{1}$, Osaeloka Ekwueme ${ }^{1}$, \\ Chinyere Okeke ${ }^{1}$, Chuka Obienu ${ }^{1}$, Ikechukwu Orakwue ${ }^{1}$
}

1. Department of Community Medicine, College of medicine, University of Nigeria.

2. Department of Obstetrics \& Gynecology, University of Jos, Nigeria.

3. Department of Psychiatry, Enugu State University Teaching Hospital.

4. Department of Pediatrics, College of medicine, University of Nigeria.

\begin{abstract}
Background: Non-use or poor usage of any form of contraception increases the chances of unwanted pregnancies, abortion and sexually transmitted infections (STIs), including HIV/AIDS occurring with attendant problems. The knowledge of, and the appropriate use of contraceptives will reduce the prevalence of unwanted pregnancies and unsafe induced abortion as well as limit incidence of STIs and associated complications.

Objectives: Determination of the opinion and use of contraceptives; to examine the socio-demographics, knowledge and attitude towards contraception and contraceptive use among medical undergraduates in the University of Nigeria, Enugu campus. Methodology: A cross-sectional study. Stratified probability sampling technique was employed using the different medical classes as strata. Individuals were subsequently chosen at random until a statistically determined sample size was achieved. Statistical Package for Social Sciences (SPSS version 20) software was utilized for data analysis.

Results: Our study found a statistically significant relationship between sex and contraceptive use. It was also statistically deduced that knowledge of possible contraceptives failure negatively impacts on opinion with regards to contraceptive use.

Conclusion: Positive opinion towards contraceptives will go a long way to encourage proper and effective contraceptives use. This can be achieved by utilizing counseling by health workers.

Keywords: Opinion, use, contraceptives, medical students.

DOI: https://dx.doi.org/10.4314/ahs.v18i3.21

Cite as: Idoko CA, Omotowo B, Anyaka C, Udo K, Ezenwosu O, Nwobi E, Ezeoke U, Obi I, Ekwneme O, Okeke C, Obienu C, Orakwne I. Opinion and use of contraceptives among medical students of the University of Nigeria, Enugu Campus. Afri Health Sci. 2018;18(3): 637-644. bttps:/ / dx.doi.org/10.4314/abs.v18i3.21
\end{abstract}

\section{Introduction}

Contraceptives use until recently has been a sensitive and controversial subject the world over more so in the tra-
Corresponding author:
Chinedu Arthur Idoko,
Department of Community Medicine,
College of medicine, University of Nigeria
Phone: 2348037219872
Email: chineduarthur@yahoo.com

ditional African society. In contemporary Nigeria, government's position on contraception has changed from a lukewarm attitude to a rather positive one. This has led to the inclusion of family planning as an integral component of maternal and child health. ${ }^{1}$

Contraception, also known as fertility control, means procedures employed to interfere, at one step or the other, with the normal sequence of events in the process of reproduction leading to a failure in conception. ${ }^{2}$ 
Various studies have shown that the non-use or poor usage of any form of contraception increases the chances of unwanted pregnancies, abortion (termination of pregnancies) and sexually transmitted diseases(STD), including HIV/AIDS occurring with their attendant problems. ${ }^{3}$ The radical change and increased sensitivity to contraceptives in Nigeria can be attributed to the increasing awareness of the government that the use of contraceptives as a means of regulating family size is an essential ingredient in socioeconomic development and a key element in population control strategies of most developed countries.

Facing up to adolescent sexuality remains a challenge in most societies. Governments in both developed and developing countries are somewhat reluctant to tackle adolescent sexual and reproductive health issues. Providing information and services for young people is still controversial despite the fact that people in many parts of the world now recognize that population policies and family planning programs have, in the past, neglected the needs of the young. ${ }^{3,45}$ Many adolescents have poor knowledge about sexuality and how to protect themselves against pregnancies and STD's. ${ }^{6}$

The world Health Organization (WHO) estimates that there are approximately 20 million of unsafe abortions every year and estimates of maternal death as a result of abortion ranged between 60,000 to 100,000 per year. $^{7}$ These unwanted pregnancies that end up in induced abortion can be prevented with consistent and correct use of contraceptives but there is a high level of ignorance among women on the use of contraceptives even amongst educated ones such as medical students. ${ }^{8,910}$ This is worsened by religious and cultural factors militating against the acceptance and use of contraceptives.

In justifying this study, the researchers looked from the perspective that the knowledge of, opinion and the appropriate use of contraceptives may go a long way in reducing the prevalence of unwanted pregnancies and unsafe induced abortion in the country. Generally, sexually active young adults are less likely to use contraception than adults and University students have been particularly identified as the most at risk for engaging in sexually risky behaviors. ${ }^{11}$
This study was conducted to determine the opinion and use of contraceptives. It also examined the socio-demographics, contraceptive use, knowledge and attitude towards contraception among medical undergraduates of the University of Nigeria, Enugu campus.

The research questions: What did undergraduate medical students know about contraceptives? What were their feelings and attitude to words contraceptives; and what were their reasons for use or non-use of contraceptives?

\section{Objectives}

To determine the attitude,knowledge and use of contraceptives among medical students of the University of Nigeria.

\section{Methodology \\ Study area}

The study was carried out at the University of Nigeria, Enugu Campus among the third to final year medical students. Enugu state lies within the semi-tropical rain forest belt in South Eastern Nigeria. It is about 223 meters above sea level with the city covering an area of $85 \mathrm{~m}^{2}$. It is bounded by Kogi and Benue states to the North, Ebonyi state to the East, Abia state to the South and Anambra state to the West. ${ }^{12}$

The literacy level is about $70 \%$ and Enugu is accessible by air and land.

Residents are predominantly Ibo by tribe and Christians. They have diverse occupations mainly business, civil service, studying, farming and others. The University of Nigeria, Enugu campus is located in the heart of Enugu Town. It has four faculties one of which is that of medical sciences. ${ }^{13}$

\section{Study population}

The population studied was the $3^{\text {rd }}$ year, $4^{\text {th }}$ year, $5^{\text {th }}$ year and $6^{\text {th }}$ year students of the Department of Medicine and Surgery of the University of Nigeria, Enugu Campus.

\section{Study design \& data collection}

A cross-sectional study using a pre-tested, semi-structured and self-administered questionnaire.

A total of 272 questionnaires were shared and 243(89\%) returned. 


\section{Sample size}

The sample size was determined using the formula (see below)for sample size determination in cross-sectional studies originally described by Daniel ${ }^{14}$ but recently highlighted by Naing et al ${ }^{15}$.Formula: $(\mathrm{Z} \alpha / 2) 2 \mathrm{P}(1-\mathrm{P}) / \mathrm{d} 2$

$\mathrm{Z}$ is the $\mathrm{Z}$-score for $95 \%$ confidence level, $\mathrm{P}$ is the assumed population prevalence, and $\mathrm{d}$ is the error. Assuming a confidence level of $95 \%$, an $\alpha$ error of $5 \%$, a prevalence of sexual activity among undergraduates in Enugu of $76.4 \%$ based on a previous study in Nigeria ${ }^{16} ; \mathrm{Z}=1.96$, $\mathrm{P}=0.8$, and $\mathrm{d}=0.05$. The minimum sample size required for the study was 272 , making provision for non-response.

\section{Sampling method}

The University of Nigeria, Enugu Campus was chosen as the study area due to convenience. The stratified probability sampling was used, utilizing the different medical classes as the strata. Individuals from the different classes/ strata were subsequently chosen at random until a determined sample size was achieved.

\section{Data analysis}

All questionnaires were checked for completeness and entered into statistical package for social sciences (SPSS version 20) software. Chi-square analysis was done and statistical significance tested. Data was summarized and presented in tables and a figure.

\section{Inclusion and exclusion criteria}

Medical students of the University of Nigeria, Enugu Campus of $3^{\text {rd }}$ to $6^{\text {th }}$ year classes who were available and willing to participate in the study were included in the study.

The students that didn't give consent were excluded from the study.

\section{Ethical consideration}

Ethical clearance was obtained from the Ethics Review Committee of the University of Nigeria Teaching Hospital, Enugu. Informed verbal consent was obtained from the participants.

\section{Results}

Table 1 shows the socio-demographic characteristics of respondents. 
Table 1: Socio-demographic characteristics

\begin{tabular}{|lll|}
\hline Characteristics & Number (Total=243) & Percentage (\%) \\
\hline Age Category & 49 & 20.2 \\
$15-20$ & 155 & 63.8 \\
$21-25$ & 35 & 14.4 \\
$26-30$ & 4 & 1.6 \\
$31-35$ & & \\
Sex & 173 & 71.2 \\
Male & 70 & 28.8 \\
Female & & \\
Tribe & 234 & 96.3 \\
ggbo & 3 & 1.2 \\
Yoruba & 1 & 0.4 \\
Hausa & 5 & 2.1 \\
Others & & \\
Religious denomination & 46 & 18.9 \\
Anglican & 117 & 47.7 \\
Catholic & 77 & 32.1 \\
Pentecostal & 1 & 0.4 \\
Traditional Religion & 2 & 0.8 \\
Others & & \\
Marital Status & 238 & 98 \\
Single & 5 & 2 \\
Married & & \\
Level of study & 59 & 24.3 \\
300 & 57 & 23.5 \\
400 & 46 & 18.9 \\
500 & 81 & 33.3 \\
600 & & \\
\hline
\end{tabular}

The $21-25$ years age group formed $63.8 \%$ of the respondents; however none of the respondents was above 35 years of age. Male respondents out-numbered females by more than a 2:1 ratio. Igbos constituted the majority. Table 2 shows that sex has a significant impact on contraceptives use.

Table 2: Sex of respondents who had previously used any contraceptive method.

\begin{tabular}{|lllll|}
\hline & & $\begin{array}{l}\text { Have you } \\
\text { before } \\
\text { NO }\end{array}$ & YES & Total \\
\hline Sex & Female & 61 & 8 & 69 \\
& Male & 131 & 43 & 174 \\
Total & 192 & 51 & 243 \\
\hline
\end{tabular}

$\mathrm{X}^{2}$ (Chi-square) $=0.041 ;$ d.f. $=4 ; \mathrm{p}<0.05$ (Significant)

Sex has a significant impact on the use of contraceptives. 
Table 3 shows the religious denominations. The denomi- with respondents' use of contraceptives.

nations did not have a statistically significant relationship Table 4 shows contraceptive failure and student's opinion.

Table 3: Respondents' religion/ denomination and feeling about contraceptive use

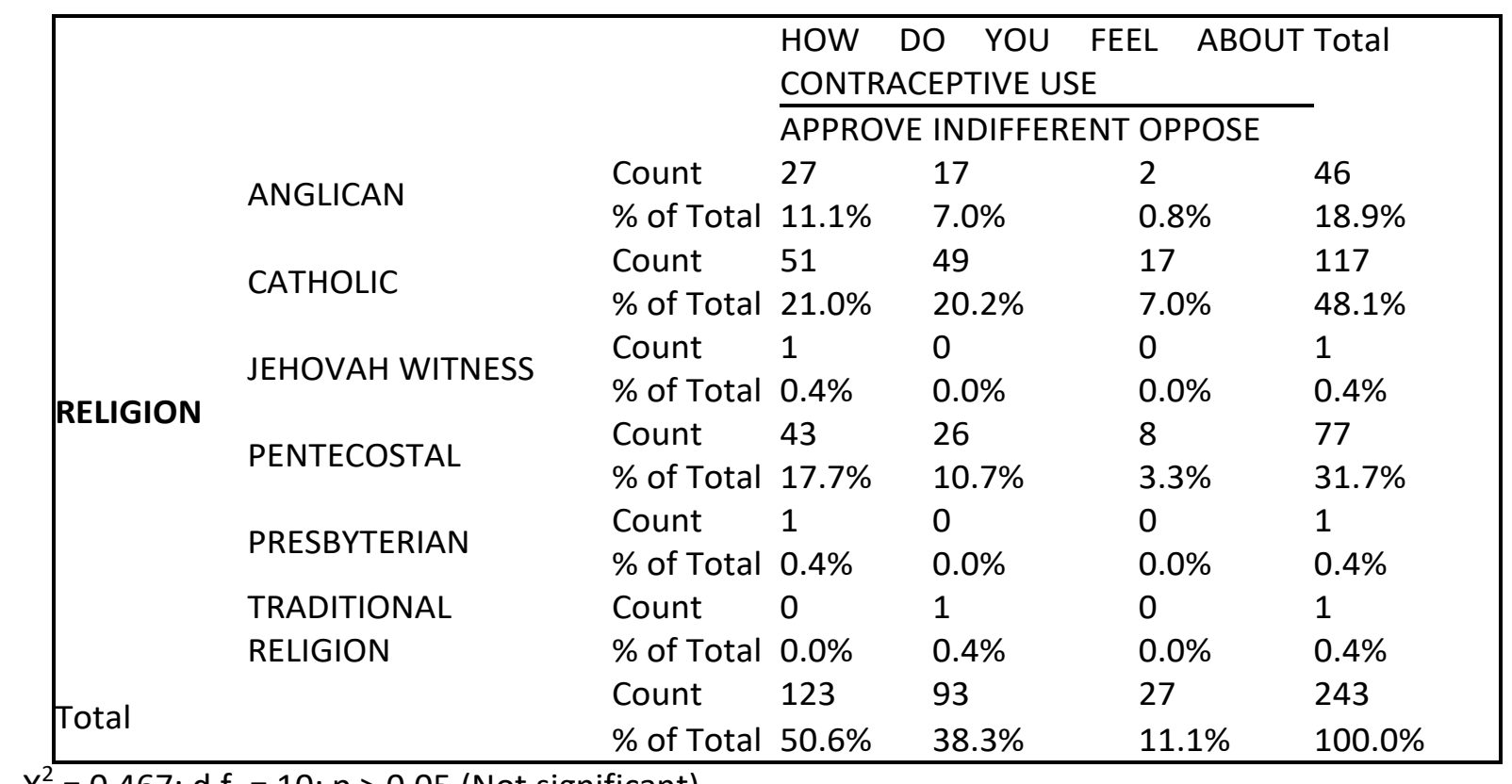

$\mathrm{X}^{2}=0.467 ;$ d.f. $=10 ; \mathrm{p}>0.05$ (Not significant)

Religion does not have a statistically significant effect on respondent's opinion on contraceptive use.

Table 4: Respondents' Knowledge of Contraceptives failure and opinion regards Contraceptive use

\begin{tabular}{|c|c|c|c|c|c|}
\hline & & & $\begin{array}{l}\text { Knowl } \\
\text { Contra }\end{array}$ & e failure & of Total \\
\hline & & & Yes & No & \\
\hline & & Count & 21 & 102 & 123 \\
\hline & & $\%$ of Total & $8.6 \%$ & $42.0 \%$ & $50.6 \%$ \\
\hline HOW DO YOU FEEL & INOIEEERENT & Count & 32 & 61 & 93 \\
\hline ABUUI & INVDIFFEREIN I & $\%$ of Total & $13.2 \%$ & $25.1 \%$ & $38.3 \%$ \\
\hline 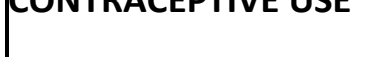 & & Count & 7 & 20 & 27 \\
\hline & UPPUSE & $\%$ of Total & $2.9 \%$ & $8.2 \%$ & $11.1 \%$ \\
\hline Tatal & & Count & 60 & 183 & 243 \\
\hline glotal & & $\%$ of Total & $24.7 \%$ & $75.3 \%$ & $100.0 \%$ \\
\hline
\end{tabular}

$X^{2}=0.014 ;$ d.f. $=2 ; p<0.05$ (Significant)

The knowledge of possible contraceptive failure negatively impacts on the opinion with regards to contraceptive use. 
Table 5 deals with reasons for non-use of contraceptives. Figure 1 shows contraceptive methods, ever used and currently used methods by respondents.

Table 5: Reasons for non-use of contraceptives by respondents

\begin{tabular}{|lll|}
\hline & Frequency & Percent \\
\hline NO RESPONSE & 220 & 90.5 \\
COST & 4 & 1.6 \\
AVAILABILITY & 7 & 2.9 \\
IGNORANCE & 2 & 0.8 \\
CHANCE & 2 & 0.8 \\
SEXUAL DISSATISFACTION & 2 & 0.8 \\
OTHERS & 3 & 1.2 \\
NO ACTIVITY & 1 & 0.4 \\
RELIGION & 2 & 0.8 \\
Total & 243 & 100.0 \\
\hline
\end{tabular}

The most common reason for non-use is unavailability (2.9\%).

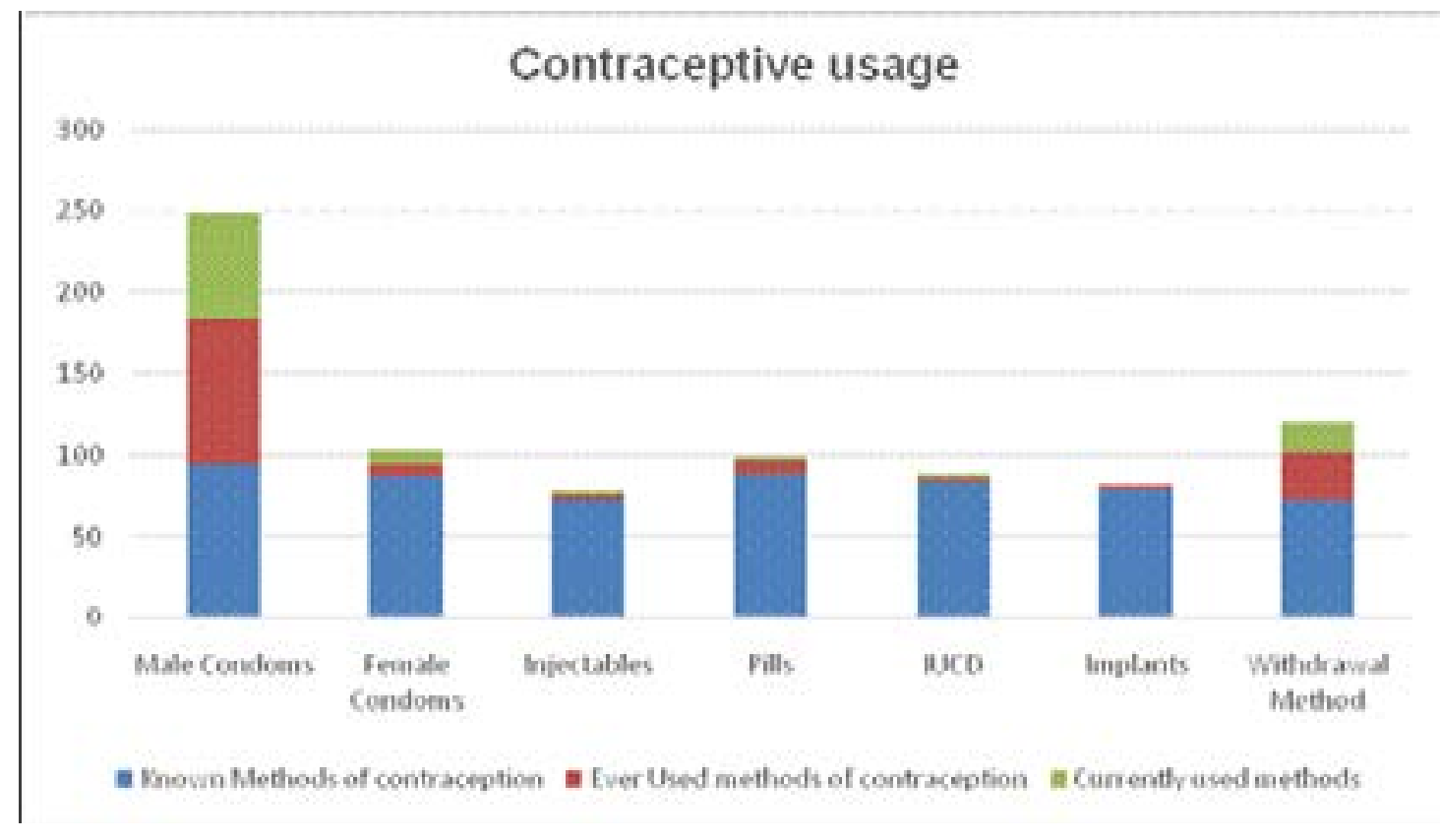

Figure 1: Complex bar chart showing contraceptive methods known by respondents, methods ever used and methods currently used by respondents.

\section{Discussion}

This study assessed the opinion and use of contraceptives among medical undergraduates of University of Nigeria, Enugu Campus, South Eastern Nigeria.

It is known that education is the strongest predictor of knowledge and attitude towards contraceptives. ${ }^{17}$ The sample population consists of medical students, so a high knowledge of issues around contraceptives was anticipated. It is known that contraceptives can fail in some instances. ${ }^{17}$ In this study, it was found that knowledge of 
this possible contraceptives failure had a negative impact on opinion to use of same. This was similar to findings from other studies where negative perceptions about contraception affected utilization. ${ }^{18,19}$

In this study, we observed that there is no clear cut influence of religion on contraceptives use. Catholics who, formed the highest percentage of opposition (7.0\%), paradoxically had the highest approval score. In fact only a small percentage of respondents disapproved the use of contraceptives solely on religious grounds. There was no significant effect of religion on respondent's opinion on contraceptives use.

The findings in this study are in contrast to those of previous studies that found that $82.2 \%$ of the participants rejected the use of contraceptives citing religious reasons and beliefs. ${ }^{20,21}$

Majority of respondents in this study were males. This could be explained by the fact that males form the majority of the medical students in the University of Nigeria. This should spur further studies on reasons for this apparent male predominance in our medical schools. In Nigeria, many young women of child bearing age still have very little knowledge of sex and sexuality. ${ }^{22}$ Sex is still a taboo subject that is rarely discussed between parents and offsprings. ${ }^{2}$ Many adolescents therefore do not look to their parents and teachers as a source of accurate information on sexuality relying on the internet, peers, with consequent misleading, incomplete or wrong information.

Young females and males joining universities often become sexually active partly due to peer-pressure, alcohol use, or as a result of a perceived sense of being in control of their social lives ${ }^{23}$. Sex in this study was found to have a significant impact on use of contraceptives.

Factors significantly associated with contraceptives use in this study are similar to those on Ugandan women where it was found that male condoms were the most commonly known and used contraceptives. ${ }^{24}$ Similar studies have been conducted in high and low income countries with similar findings. ${ }^{25,26}$

Low usage of other methods may be attributable to the fact that majority of the sample population are adolescents and unmarried youths who are more likely to use male condoms than other forms of contraception.

Reasons for non-use of contraceptives included cost, availability, ignorance, and sexual dissatisfaction. Most common reason for non-use was found to be non-availability which is similar to a previous study done in Nigeria. $^{27}$

\section{Study limitations}

The research topic required a number of private as well as sensitive questions to which some respondents didn't feel quite comfortable responding The respondents were therefore reassured of confidentiality of their identity and responses. Participant's names were not needed since questionnaires identification was with numbers.

At the time of data collection, most students were away on school holiday.

\section{Conclusion}

This study revealed a significant relationship between opinion towards contraceptives and use of contraceptives. Positive opinion towards contraceptives use would go a long way in encouraging improved, proper and effective contraceptive use. There is need to educate and counsel the students on sexuality, modern methods of contraception, and consider access to contraceptives as a fundamental human right.

\section{Acknowledgments}

We wish to appreciate the Head, Department of Community Medicine, University of Nigeria for the enabling collaborative environment created in the department.

Thanks to the assistants that supported logistics and data collection.

Love to my wife Mrs Chinelo Idoko and lovely kids Arthur, Adriel and Adaoma Idoko for the peace and love enjoyed at home which is helpful to my professional and academic pursuits.

Thanks to African Health Sciences for the opportunity to submit this work.

\section{References}

1. FMOH Abuja. Data sheet on reproductive health situation in Nigeria. 2003; pp. 4-18.

2. Clerk NT, Ladipo OA. Contraception. [book auth.] Akin Agboola. Textbook of obstetrics and Gynaecology for Medical Students $2^{\text {nd }}$ Edition. Ibadan.

3. Fawole OI, Asuzu MC, Oduntan SO. Survey of knowledge, attitudes and sexual practices relating to HIV/AIDS infection among Nigerian secondary school students. Afri J Reprod Health. 1999; 3: 15-24.

4. Bernard, Schwartz AJ. Impact of human sexuality pro- 
gram on sex-related knowledge, attitudes, behaviour, and guilt of college undergraduates. Journal of the American College Health Association. 1977; 25: 185-5.

Christopher FS. Adolescent PregnancyPrevention. Family Relations 1995; 44: 384-91 PubMed .

5. Allgeier ER, Allgeier AR. Sexual interactions. $2^{\text {nd }}$ ed. Lexington (MA): DC Health; 1988.

6. Nwagha U. Induced Abortion and A Bernstein PS, Rosenfield A. Abortion and Maternal Health. Int J Gynaecol Obstet. 1998 Dec; 1(63):S115-22. Bortion Laws in Nigeria. 2014, p. 3.

7. Bernstein PS, Rosenfield A. Abortion and Maternal Health. Int J Gynaecol Obstet. 1998 Dec; 1(63):S115-22

8. Adegbenga MS, Dipelo M, Babalola S, Otu DA. Repropductive knowledge, sexual behaviour and Contraceptive Use among Adolescents in Niger State of Nigeria. Afri J. Reprod Health. 2003; 7: 36-48 PubMed .

9. Araoye MO. Sex, Contraception and fertility among Inschool Adolescents in Ilorin. Journal of Community Medicine and Primary Health Care. 1998; 10: 21-31.

10. Izuagbara CO. Tasting the forbidden fruit: The Social Context of First Sexual Intercourse among Young Persons in a rural Nigerian community. Afri J. Reprod Health. 2001; 5 (2): 22 PubMed -29.

11. Cohen A. Sexual Risk Behaviors: Who Is Vulnerable? An Extensive Literature Review Of Sexual Risk Practices And The Development Of A Pamphlet For An At-Risk Community. Seattle: Unpublished Phd Thesis Presented At Antioch University Seattle, 2009.

12. Ilechukwu GC, Ilechukwu CGA, Ubesie AC, Onyire NB, Emechebe G, Eze JC. Relationship Between Nutritional Status and Intensity of Common Intestinal Helminthes Among Children in Enugu, South-East Nigeria. Ann Med Health Sci Res. 2014; 4(2): 119-112.

13. UNEC-University of Nigeria Nsukka [internet] Available at: http"//www.unn.edu.ng/campuses/unec. (assessed November 2016).

14. Daniel WW. Bustatrsties:.A Foundation for Analysis in the Health Sciences. $7^{\text {th }}$ edition. New York: John Witey and Sons; 1999.

15. Naing L, Winn T, Rusli BN. Practical issues in calculating the sample size for prevalence studies. Archives of Orofacial Sciences. 2006;1:9-14.

16. Okafor II, Obi SN. Sexual risk behaviour among un- dergraduate students in Enugu, Nigeria. J Obstet Gynaecol. 2005;25(6):592-595.

17. Association for Reproductive and Family Health (ARFH). The West African Youth Initiative: Promoting Change in Adolescent Health through Peer Education ARFH Monograph. ARFH Monograph Series, No 3. 1998.

18. Ochako R, Mbando M, Aloo S, Kaimenyi S, Thompson $\mathrm{R}$, Temmerman $\mathrm{M}$, et al. Barriers to modern contraceptive methods uptake among young women in Kenya: a qualitative study. BMC Public Health. 2015;15(1):118.

19. Agyei WK, Migadde M. Demographic and sociocultural factors influencing contraceptive use in Uganda. Journal of Biosocial Science. 1995;27(1):47-60.

20. Ezenwanne, et al. Knowledge, Attitude and Practice of Contraception among UNEC Students: Comparison of Males and Females. Enugu: s.n., 2006.

21. Mehra D, Agardh A, Petterson KO, Ostergren PO. Non-use of contraception: determinants among Ugandan university students. Global Health Action. 2012;5:18599.

22. Idonije BO, Oluba OM and Otamere HO. A Study on Knowledge, Attitude and Practice of Contraception among Secondary School Students in Ekpoma, Nigeria. 6, Ekpoma: JCPS, 2011, Vol. 2.

23. Tura G, Alemseged F, Dejene S. Risky sexual Behavior and Predisposing Factors among Students of Jimma University, Ethiopia. Ethiopian Journal of Health Sciences. 2012;22(3):170-80.

24. Asiimwe JB, Ndugga P, Mushomi J, Manyenye Ntozi JP. Factors associated with modern contraceptive use among young and older women in Uganda; a comparative analysis. BMC Public Health. 2014;14:926.

25. Simbar M, Tehrani FR, Hashemi Z. Reproductive health knowledge, attitudes and practices of Iranian college students. Eastern Mediterranean Health Journal. 2005;11(5-6):888-97.

26. Dinas K, Hatzipantelis E, Mavromatidis G, Zepiridis L, Tzafettas J. Knowledge and practice of contraception among Greek female medical students. Eur J Contracep Reprod Health care. 2008;13(1):77-82.

27. Cadmus E, Owoaje E. Patterns of Contraceptive Use Among Female Undergraduates In The University of Ibadan, Nigeria. Internet Journal of Health. 2009 Volume 10 Number 2. 